\title{
Happiness to be gained in paediatric asthma care
}

\author{
B.C.T. Flapper*, E.J. Duiverman*, J. Gerritsen*, K. Postema* and \\ C.P. van der Schans ${ }^{\uparrow,+}$
}

ABSTRACT: The aim of the present study was to establish the efficacy in terms of morbidity and health-related quality of life (HRQoL) of a group asthma education-exercise programme to children with low (below 10th percentile value) quality-of-life scores.

A controlled, randomised, open, clinical trial was conducted. In total, 36 out of 53 unhappy children, among 204 (68\%) respondents, treated in four paediatric practices, enrolled (mean age 10 yrs; range: 8-12 yrs), after random allocation in control and intervention groups (child, parent, teacher). Measurements were taken at baseline (T0) and after 3, 6 (T6) and 9 months (T9; intervention group only at 9 months). All but four controls completed the study.

From T0-T6, changes $(\Delta)$ in HRQoL were clinically important and significantly greater in the intervention group than in the control group, both for generic HRQoL (effect size (ES) $0.95 ; \Delta$ $16 \% \pm 12 \%$ versus $-1 \pm 4 \%$ ) and for asthma-specific HRQoL (ES $0.58 ; \Delta 15 \% \pm 17 \%$ versus $1.5 \pm 14 \%$ ). T9 measurements were consistent with T6 findings. Changes in sick days (ES 0.78 ), oral prednisone courses (ES 0.71 ) and doctor visits (ES 0.74 ) over a 6-month period were greater in the intervention group than in the control group. Changes could not be ascribed to change in lung function or medication.

In unhappy children, quality of life and morbidity may improve with a low intensity asthma education-exercise programme, even without gains in pulmonary function or exercise tolerance.

KEYWORDS: Asthma, childhood, education, physical exercise, pulmonary rehabilitation, quality of life

\begin{abstract}
A sthma is one of the most common chronic diseases in childhood [1, 2]. With modern treatment, children with asthma in paediatric care may experience a normal life [3]. Therefore, the prevalence of low well-being (quality-oflife scores below the 10th percentile value (P10)) is not expected to be elevated. In a study in Europe, half of children with asthma had persistent symptoms [4] that may lower their well-being. Well-being can be measured as generic healthrelated quality of life (HRQoL). The current authors' screening of well-being in children treated in four paediatric asthma practices showed 2.5 times (25\%)the normal prevalence of low well-being. As generic HRQoL is a measure of happiness, children who reported a low HRQoL level (quality-of-life score $<$ P10) related to asthma were considered to be unhappy, and to be candidates for an intervention aimed at increasing happiness.
\end{abstract}

Improvement of generic HRQoL can be sought through better self-management of asthma. The favourable effects on morbidity of asthma educational programmes and of exercise programmes have been described previously [5-10], but no intervention study has evaluated the impact of education and exercise on quality of life in children.

A programme that includes both education and exercise has been shown to have favourable effects on HRQoL in adults [6]. The current authors developed an exercise programme, superimposed on an education programme that had been validated previously [8]. The purpose was to familiarise the child and parents with management of asthma at home, in school and in sports.

The objective of the present study was to establish the efficacy, in terms of morbidity and HRQoL, of this group asthma education-exercise programme, offered to children who remained unhappy despite regular asthma care offered in a paediatric practice.

The current authors' hypothesis was that generic well-being, HRQoL and morbidity can be improved with this intervention.

\section{AFFILIATIONS}

*Dept of Paediatrics, and,

\#Centre for Rehabilitation, University Medical Centre Groningen,

${ }^{+}$Dept of Health Sciences, University of Groningen, and

-Hanze University Applied Sciences, Groningen, The Netherlands.

CORRESPONDENCE

B.C.T. Flapper

Beatrix Children's Hospital/ Dept of Paediatrics

University Medical Centre Groningen P.0. Box 30.001

9700 RB Groningen

The Netherlands

Fax: 31503611704

E-mail: b.flapper@bkk.umcg.nl

Received:

October 242007

Accepted after revision:

June 302008

SUPPORT STATEMENT

The present study was supported by de Vereniging Beatrix Noord Nederland (Haren, The Netherlands).

STATEMENT OF INTEREST

None declared.

European Respiratory Journal Print ISSN 0903-1936 Online ISSN 1399-3003 


\section{METHODS}

\section{Setting and sample}

This open randomised controlled trial (fig. 1) was conducted in the Child Rehabilitation Centre (Beatrixoord, Haren, The Netherlands), a tertiary ambulatory clinic, between January 2004 and September 2005.

The accessible population was defined as any child 7-12 yrs old with asthma visiting four paediatric asthma clinics in the region. The parents of all subjects were sent a letter introducing the screening of HRQoL [11-15], including a preaddressed and stamped reply envelope.

The response rate was $68 \%$. Children who had a generic HRQoL score $<$ P10 in the self-report form $(26 \%)$ were selected. The parents of these children were telephoned to verify that low well-being was not caused by a recent asthma exacerbation, another chronic disorder or any cause of unhappiness. Parents were sent a letter introducing the study and an invitation to participate in the study.

Participants were assigned randomly to a control group and an intervention group. Both groups continued regular care and visits to the referring paediatrician and asthma nurse. In addition, the intervention group received a 3-month training programme. The intervention tested was group educationexercise for the child, and education to caregivers and schoolteachers.

Inclusion criteria for the current study were: total generic HRQoL score $<$ P10, age 7-12 yrs, diagnosed asthma based on international criteria (American Thoracic Society [16]), use of asthma medication according to guidelines, no recent asthma diagnosis, exacerbation or infection.

Exclusion criteria were other causes of low HRQoL and cognitive level $<7$ yrs.

\section{Data collection}

The paediatrician and the asthma nurse at the centre took the history, and performed a physical examination and inhalation test at baseline (T0), after the 3 month intervention or control period (T3) and 3 months after discharge (T6). Medication was adjusted at T0, if judged necessary by the paediatrician for practical reasons (better timing), or for newly found exercise intolerance (measured using the exercise-induced bronchoconstriction (EIB) test) [17]. Adjustments were made

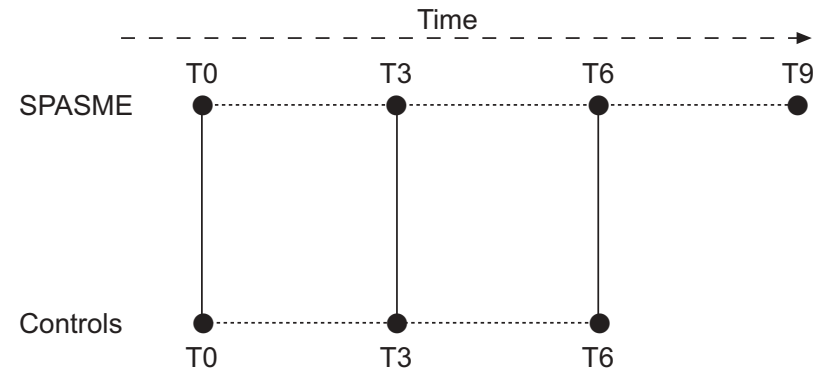

FIGURE 1. The Secondary Prevention of Asthma by Movement and Exercise (SPASME) intervention. T0: baseline; T3: 3 months; T6: 6 months; T9: 9 months. —. comparisons between control and intervention groups. - - - - : Iongitudinal comparison. according to guidelines from the Dutch Paediatric Respiratory Society [18].

As a measure of lung function, forced expiratory volume in one second (FEV1; \% predicted) and the FEV1/forced vital capacity (FVC), performed at T0 and T3. Exercise intolerance was determined using the EIB test (fall in FEV1 during the test, cut-off 10\%) [17].

Exercise tolerance was related to distance run in the EIB test and a 6-min running test indoors.

Morbidity parameters over the previous 6-month period consisted of: asthma severity score (on a Likert scale from low (1) to severe (7)); number of visits to the general physician, emergency room and hospital; number of asthma attacks and of oral steroid courses; and days absent from school (child) or work (parent), as reported by parents.

Demographic data included sex, age, weight, length of the child, parental age, educational level and employment status of the parents.

HRQoL measures were taken at T0, T3 and T6 and 6 months after discharge (T9). Only the intervention group completed the T9 measurement.

The Dutch Children Academisch Ziekenhuis Leiden (AZL; Academic Hospital Leiden, now called University Medical Centre Leiden)-Toegepast-Natuurwetenschappelijk Onderzoek (TNO; National Research Institute for Prevention and Health) Quality of Life questionnaire (DUCATQOL; also called DUX-25) [11], and the TNO-AZL Children Quality of Life questionnaire (TACQOL; both the generic [12-14] and asthma-specific [15] modules) were used. The DUX-25 [11] collects information in four domains (physical, at-home functioning, emotional and social). The DUX-25 score has discriminative properties (Crohnbach alpha 0.94) and was used to recognise children with a level of well-being below the P10 of the reference population (DUX-25 total score $<63$ ). Children with a self-reported DUX-25-score $<\mathrm{P} 10$ were considered unhappy.

The TACQOL generic questionnaire [12-14] evaluates five domains (physical, motor, autonomic, school and social functioning) and two moods (positive and negative).

The TACQOL asthma questionnaire [15] evaluates five domains (complaints, emotions, situations, treatment and medication demands). For the purpose of the present study, a TACQOL total score (summation of domain scores) was calculated.

In the two TACQOL questionnaires [12-15], HRQoL scores are influenced by both the presence and the perception (the emotional response) of having a health problem. Responses are combined into a single score (fig. 2), that can either be favourable, in the absence of problems (4) and in the presence of health problems that are "fine" (3), or unfavourable in the presence of problems that are perceived as "(quite) bad" (1-0).

Raw quality-of-life scores were adapted to represent percentages of the maximum possible DUX-25 and TACQOL domain scores. Higher scores indicate better HRQoL, in both questionnaires. 


\begin{tabular}{|c|c|c|}
\hline Sho & Never & $\underbrace{\text { Occasionally Often }}_{1}$ \\
\hline & & $\begin{array}{l}\text { At that time my child/l felt } \\
\text { fine not quite bad } \\
\text { so good bad }\end{array}$ \\
\hline Score & 4 & 2 \\
\hline
\end{tabular}

FIGURE 2. The scoring system for the Toegepast-Natuurwetenschappelijk Onderzoek-Academisch Ziekenhuis Leiden Children Quality of Life (TACQOLasthma) questionnaire.

\section{The intervention}

The education-exercise programme was based on the view [9, $10,19]$ that education by play and exercise are natural modes of communication for pre-adolescent children [9, 19]. As group education may be more effective in children [9, 19], the education-exercise programme was offered to groups of 8-10 children, in ten weekly sessions of $1.5 \mathrm{~h}$ of education and $1 \mathrm{~h}$ of exercise, and in a follow-up session at T6, 3 months after discharge. Parents followed five educational sessions (duration $1.5 \mathrm{~h}$ ), every 2 weeks. Teachers attended one 1.5-h session.

The programme was offered by a paediatric nurse and child physiotherapist trained in the original educational programme by ColLAND [8]. This programme has been evaluated and validated [8] previously, and uses games and learning materials designed specifically for the school age group (712 yrs). Educational themes were offered in a 2-way dialogue setting, as described in the original study [8]. Both group education and individual advice and reassurance [17] on capability to perform activities in daily life and sports were offered.

A physical exercise programme was added using elements of other exercise programmes, as reviewed by VeLDHOVEN [10]. Contrary to other programmes, the current authors' exercise programme had no focus on improving exercise tolerance, for which a higher frequency (three times per week) of training is needed.

Written informed consent for the study was obtained from the parents of all responding children, as well as from 12-yr-old children themselves.

The Medical Ethical Board of the University Medical Centre Groningen (Groningen, The Netherlands) and the participating referral hospitals approved the study.

\section{Analysis}

The sample size was calculated using a sample size analysis to determine the number of children needed for the study effect [20]. A difference of $1 \mathrm{SD}$, a power of $80 \%$ and a significance level of $5 \%$ was used to calculate sample size. Based on these assumptions, the number of patients required was 32 .

Allocation to the intervention group or the control group was done using the minimisation procedure by age, sex and lung function (FEV1 $>85 \%$ pred, or FEV1 $\leqslant 85 \%$ pred) [20]. This procedure is an adequate method for blind group allocation in small samples. The principle of analysis by intention to treat was followed.

Changes in HRQoL scores were calculated between T0 and T3 and between $\mathrm{T} 0$ and $\mathrm{T} 6$.

Changes in morbidity were calculated over the 6-month periods prior to and following $\mathrm{T} 0$, but data were corrected to a 1-yr period.

Comparison between groups on HRQoL changes and morbidity changes was performed using the Mann-Whitney test.

Within the intervention group, morbidity and quality-of-life scores before and after T0 were analysed pairwise, using the Wilcoxon test [20].

Adjustment for age, sex, educational level of caregivers and severity of asthma was not performed, as no differences between groups were found.

The recommendations by MiDDEL et al. [21] were followed to study the magnitude (effect size) of HRQoL changes between T0-T3, T0-T6 or T0-T9 [21]. Changes with an effect size of 0.50 or more were defined as "clinically important" [21].

For all tests, a level of significance of $p<0.05$, two-sided, was used. Data are presented as mean $\pm \mathrm{SD}$, unless otherwise stated.

\section{RESULTS}

Out of 301 children approached (fig. 3), 204 (67.8\%) provided complete responses. A well-being level of $>\mathrm{P} 10$ was seen in $74 \%$, and of $<\mathrm{P} 10$ in $26 \%$. Differences in well-being levels

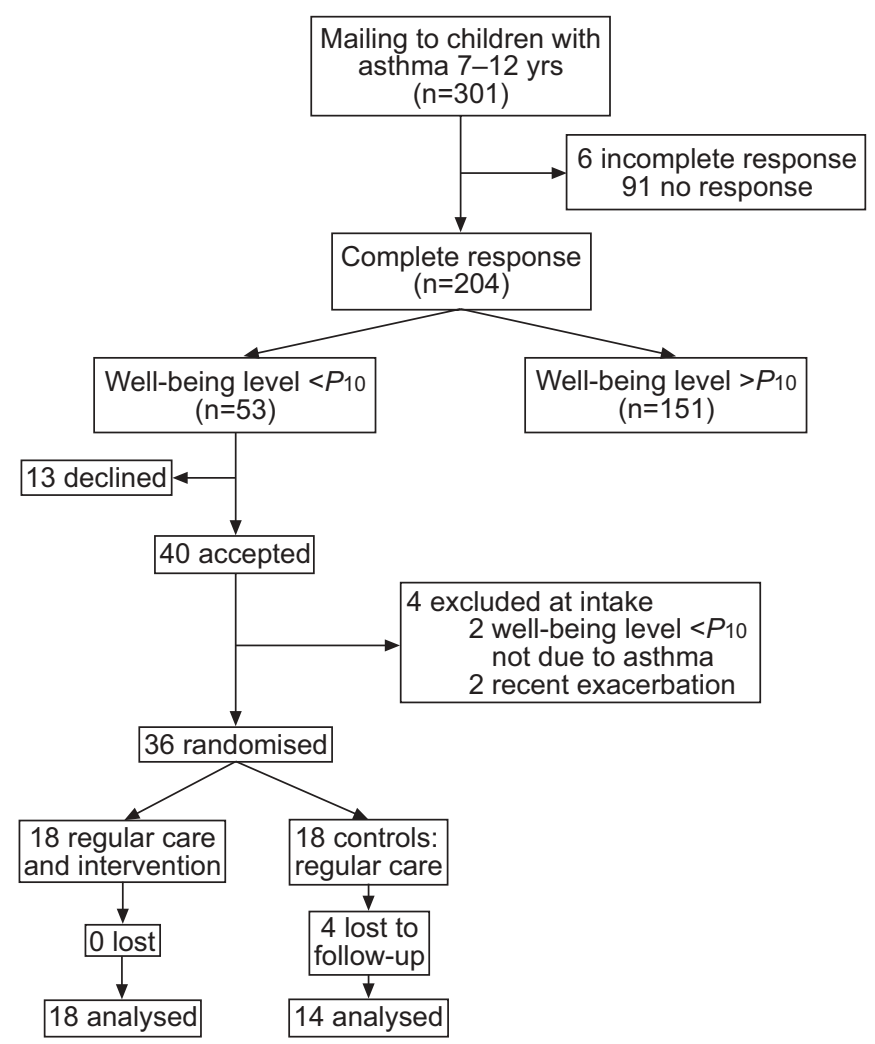

FIGURE 3. Flow diagram showing progress through the phases of the study $P$ 10: 10th percentile value. 
between the children with scores below or above the cut-off score were not explained by differences in morbidity parameters or in lung function values.

Out of the 53 unhappy children invited to participate in the study, 40 enrolled.

Asthma severity, medication used and prevalence of low DUX25 total score did not differ significantly between participants from the different hospitals.

Parents gave a mean \pm SD asthma severity score of $4.5 \pm 2.8$ on a Likert scale of 1-7 (1 not severe, 7 severe). The paediatrician classified children's asthma as moderate-to-severe, and persistent [18]. They had been treated according to guidelines [18]. Lung function values were in the normal range (FEV1 and FEV1/FVC $4.6 \%$ and $3.5 \%$, respectively, below predicted values).

The mean \pm SD age was $10 \pm 1$ yrs, length $147 \pm 3 \mathrm{~cm}$ and weight $40 \pm 2 \mathrm{~kg}$. Overall, 53\% were male. Parental age was $35 \pm 3$ yrs. At least one parent was employed in $92 \%$ of cases, while $8 \%$ were dependent on social security. A total of $30 \%$ had received previous education sessions. As expected, DUX25 total score was significantly lower $(56.9 \pm 11.5)$ than the norm $(78 \pm 13 ; \mathrm{p}<0.001)$.

At T0, two children in each group had to be excluded: two had recently acquired another chronic disorder prevailing over asthma, and two had a recent exacerbation. The 36 remaining children were divided between the control and intervention groups after minimisation [20].

\section{Comparisons between intervention and control groups}

At T0, pulmonary function did not differ between groups, neither in FEV1 (control group 95.6 $\pm 13.5 \%$ pred; intervention group $98.6 \pm 11.4 \%$ pred), FEV1/FVC (control group $84.5 \pm 8 \%$; intervention group $84.5 \pm 9 \%$ ). Over the following 3 months, pulmonary function did not improve significantly in either groups.

T0 running distance did not differ between groups, and did not change between $\mathrm{T} 0$ and T3. It was measured in the EIB test (control group $750 \pm 158 \mathrm{~m}$; intervention group $744 \pm 232 \mathrm{~m}$ ), and in the 6-min indoor running test $(1000 \pm 400 \mathrm{~m}$ in both groups).

In three new EIB cases, medication adaptation led to an improvement in FEV1 fall in the EIB test, consistent with disappearance of secondary exercise intolerance (T0: fall $15 \pm 11 \%$; T3: fall $6.7 \pm 13 \%$ ).

Optimisation of medication was applied for better timing of medication in four children, and for newly diagnosed EIB in six cases, spread between the intervention and control groups. Comparison between those without and those with medication alteration, on changes in morbidity and HRQoL (T0-T6), showed no differences, but the groups were too small to draw reliable conclusions.

At T0, morbidity parameters between the intervention and control group did not differ (table 1); nor did asthma severity score (control group 4.2 \pm 2.7 ; intervention group $4.9 \pm 2.8$ on a Likert scale ranging $1-7$ ).

Comparison between groups on changes in morbidity parameters over the 6-month period between T0-T6 (table 1) showed greater changes in the intervention than in the control group for visits to the general physician and paediatrician (effect size 0.71), oral steroid (prednisone) courses (effect size 0.71 ), and days absent from school (effect size 0.74).

HRQoL scores at T0 did not differ between the intervention and control groups.

Comparison of changes in HRQoL over the 3-month period between T0-T3 (table 2), showed greater changes in HRQoL in the intervention group than in the control group, for two selfreported total scores (DUX-25 and TACQOL-asthma) and for four proxy-reported domains (TACQOL-asthma situations and TACQOL-generic motor, autonomic and cognitive domains).

Comparison of changes in HRQoL over the 6-month period between T0-T6 (table 3), showed greater changes in HRQoL in the intervention-group than in the control-group, for almost all self and proxy reported HRQoL-domains.

Comparison of changes over time between T0-T6 within the intervention group (table 4) showed changes with effect size greater than $0.05 \mathrm{SD}$ that were of clinical importance, for all

TABLE 1 Morbidity at baseline (T0) and changes over a 6-month period in the intervention and control groups

\begin{tabular}{|c|c|c|c|c|c|c|}
\hline & \multicolumn{3}{|c|}{ то } & \multicolumn{3}{|c|}{$\Delta \mathrm{TO}-\mathrm{T} 6$} \\
\hline & Intervention & Control & p-value & Intervention & Control & $\mathrm{p}$-value \\
\hline Extra visits to general physician & $3.8 \pm 4.8$ & $2.4 \pm 2.8$ & 0.44 & $2.9 \pm 5.3$ & $1.4 \pm 1.7$ & 0.001 \\
\hline Visits paediatrician & $4.2 \pm 3.4$ & $2.1 \pm 3.0$ & 0.06 & $1.5 \pm 4.6$ & $-0.54 \pm 1.1$ & 0.03 \\
\hline Hospital admissions & $0.6 \pm 2.2$ & $0.5 \pm 1.9$ & 0.83 & $0.5 \pm 2.4$ & $-0.23 \pm 0.1$ & 0.31 \\
\hline Days absent from school & $7.4 \pm 11.2$ & $6.8 \pm 9.0$ & 0.92 & $7.2 \pm 11.1$ & $-2.4 \pm 5.1$ & 0.04 \\
\hline Days parent home from work & $4.3 \pm 8.5$ & $6.2 \pm 10.1$ & 0.65 & $4.6 \pm 9.3$ & $3.3 \pm 6.0$ & 0.38 \\
\hline
\end{tabular}

Numbers per year are presented as mean \pm SD, unless otherwise stated. Data per 6-months were adjusted to a 1-yr period. $\Delta$ : change between the 6-month period prior to and after T0; T6: 6 months after T0. $p$-values were calculated using the Mann-Whitney test between groups. $p<0.05$ was regarded as significant. 
TABLE 2 Changes in quality of life over a 3-month period from baseline in the intervention and control groups

\begin{tabular}{|c|c|c|c|c|c|c|}
\hline & \multicolumn{3}{|c|}{ Children } & \multicolumn{3}{|c|}{ Parents } \\
\hline & Intervention group & Control group & p-value & Intervention group & Control group & p-value \\
\hline \multicolumn{7}{|l|}{ DUX-25 } \\
\hline Physical functioning & $15.5 \pm 18.3$ & $4.9 \pm 13.8$ & 0.11 & $6.5 \pm 16.6$ & $0.35 \pm 17.1$ & 0.35 \\
\hline Functioning at home & $15.5 \pm 13.8$ & $7.9 \pm 8.3$ & 0.15 & $10.0 \pm 21.0$ & $0.45 \pm 14.0$ & 0.26 \\
\hline Total score & $16.7 \pm 12.0$ & $5.7 \pm 11.8$ & 0.02 & $12.1 \pm 18.1$ & $0.64 \pm 15.2$ & 0.11 \\
\hline \multicolumn{7}{|l|}{ TACQOL } \\
\hline Physical functioning & $12.2 \pm 23.0$ & $2.5 \pm 27.5$ & 0.35 & $4.5 \pm 17.4$ & $-3.1 \pm 23.1$ & 0.37 \\
\hline Motor functioning & $7.9 \pm 19.9$ & $3.4 \pm 8.2$ & 0.81 & $6.2 \pm 7.6$ & $-3.4 \pm 16.0$ & 0.023 \\
\hline Autonomy & $7.4 \pm 23.9$ & $2.1 \pm 7.7$ & 0.97 & $6.2 \pm 8.0$ & $-1.2 \pm 7.5$ & 0.05 \\
\hline Cognitive functioning & $6.2 \pm 22.1$ & $1.1 \pm 13.0$ & 0.36 & $6.9 \pm 19.5$ & $-8.8 \pm 15.9$ & 0.05 \\
\hline \multicolumn{7}{|l|}{ TACQOL-asthma } \\
\hline Complaints & $10.6 \pm 23.4$ & $-4.2 \pm 25.7$ & 0.59 & $10.6 \pm 23.3$ & $-2.5 \pm 25.6$ & 0.22 \\
\hline Emotions & $10.1 \pm 19.5$ & $-4.2 \pm 13.7$ & 0.17 & $8.5 \pm 16.3$ & $-1.9 \pm 18.6$ & 0.12 \\
\hline Situations & $13.5 \pm 24.2$ & $-2.1 \pm 17.3$ & 0.11 & $11.3 \pm 19.1$ & $-3.9 \pm 13.6$ & 0.03 \\
\hline Treatment & $9.9 \pm 20.9$ & $-4.9 \pm 17.9$ & 0.15 & $7.3 \pm 21.7$ & $2.1 \pm 6.6$ & 0.20 \\
\hline Medication & $3.1 \pm 22.3$ & $0.7 \pm 13.6$ & 0.98 & $7.2 \pm 18.0$ & $-5.8 \pm 16.7$ & 0.28 \\
\hline Total score & $15.1 \pm 17.2$ & $-2.9 \pm 10.0$ & 0.023 & $9.3 \pm 14.5$ & $2.1 \pm 13.7$ & 0.10 \\
\hline
\end{tabular}

Data are change in quality of life, presented as mean $\pm \mathrm{SD}$, unless otherwise stated. DUX-25: the Dutch Children Academisch Ziekenhuis Leiden (AZL)-ToegepastNatuurwetenschappelijk Onderzoek (TNO) Quality of Life questionnaire; TACQOL: the TNO-AZL Children Quality of Life questionnaire. p-values were calculated using the Mann-Whitney test between groups. $\mathrm{p}<0.05$ was regarded as significant.

total HRQoL scores, in eight out of 16 child-reported, and 12 out of 16 parent-reported domains. Changes in HRQoL scores over a longer period (T0-T9) were consistent with findings at T6, but were available in only 9 out of 18 children. No reliable conclusions could be drawn.

During the study period, the drop-out percentage was surprisingly low. All children in the intervention group, and 14 children in the control group completed 6 months' followup measurements. Attendance in the intervention group was $84.5 \%$ for children and $79.4 \%$ for parents, absence being due to sick leave for viral infections. Attendance by teachers was $42 \%$.

\section{DISCUSSION}

As far as the current authors are aware, the present study is the first paediatric study to show improvements in quality of life following a 3-month asthma education-exercise programme. In school-age children with low scores in an initial generic HRQoL self-report, clear improvements in HRQoL and reductions in oral steroid courses, school absence and doctor visits are seen following the intervention. These may not be mediated simply by changes in medication control or in clinical parameters.

The effects of asthma educational programmes on morbidity in children [5, 7-9], evaluated in a recent meta-analysis [5], showed reduced morbidity, emergency room visits and days absent from school. Using the educational programme of COLLAND [8], the present authors replicated reductions of paediatric visits and school absenteeism as shown in other studies [5, 8-9].

The effects on HRQoL of a combination of education and exercise have not been studied in children. In accordance with an adult education-exercise program [6], the present authors showed that HRQoL, both asthma-specific and generic, can improve significantly, even when gains in pulmonary function or exercise tolerance are not demonstrated.

The effects seen immediately after the current programme were smaller than those 3 or 6 months later. These late effects may be understandable from the nature of HRQoL, which evaluates functioning in physical, personal and social domains of daily life. It is likely that the process of self-management takes time to accomplish effects in all aspects of daily life, and therefore HRQoL effects may need time to develop.

The present authors found one randomised controlled trial of group education in a large population of children with asthma that did show effects on morbidity, but not on disease-specific HRQoL [22]. Children in the study had a relatively high HRQoL at the start of the study, and they received three sessions (45-60 $\mathrm{min}$ ) of education, as opposed to the present unhappy group, which received 10 sessions [22]. 
TABLE 3 Changes in quality-of-life over a 6-month period from baseline in the intervention and control groups

\begin{tabular}{|c|c|c|c|c|c|c|}
\hline & \multicolumn{3}{|c|}{ Children } & \multicolumn{3}{|c|}{ Parents } \\
\hline & Intervention group & Control group & p-value & Intervention group & Control group & $\mathrm{p}$-value \\
\hline \multicolumn{7}{|l|}{ DUX-25 } \\
\hline Physical functioning & $16.9 \pm 16.8$ & $-3.0 \pm 8.9$ & 0.001 & $10.4 \pm 15.2$ & $-1.5 \pm 7.9$ & 0.019 \\
\hline Functioning at home & $17.5 \pm 16.9$ & $-1.4 \pm 5.7$ & $<0.0005$ & $16.2 \pm 15.4$ & $-1.4 \pm 6.9$ & 0.001 \\
\hline Total score & $16.2 \pm 12.2$ & $-1.1 \pm 3.6$ & $<0.0005$ & $16.2 \pm 9.7$ & $0.0 \pm 2.4$ & $<0.0005$ \\
\hline \multicolumn{7}{|l|}{ TACQOL } \\
\hline Physical functioning & $14.1 \pm 20.8$ & $0.0 \pm 10.7$ & 0.027 & $9.4 \pm 19.8$ & $0.4 \pm 13.5$ & 0.3 \\
\hline Motor functioning & $17.4 \pm 22.9$ & $-4.0 \pm 13.2$ & 0.002 & $10.7 \pm 13.1$ & $0.0 \pm 2.7$ & 0.006 \\
\hline Autonomy & $12.0 \pm 22.8$ & $-1.9 \pm 7.9$ & 0.022 & $8.3 \pm 11.4$ & $0.4 \pm 1.7$ & 0.005 \\
\hline Cognitive functioning & $7.3 \pm 13.7$ & $-1.4 \pm 6.2$ & 0.048 & $5.8 \pm 13.5$ & $0.9 \pm 3.3$ & 0.91 \\
\hline \multicolumn{7}{|l|}{ TACQOL-asthma } \\
\hline Complaints & $12.3 \pm 21.1$ & $0.6 \pm 8.1$ & 0.014 & $17.8 \pm 21.8$ & $-0.4 \pm 9.6$ & 0.004 \\
\hline Emotions & $15.9 \pm 25.5$ & $-1.4 \pm 16.7$ & 0.108 & $14.8 \pm 18.6$ & $0.9 \pm 3.8$ & 0.013 \\
\hline Situations & $14.3 \pm 25.3$ & $-2.6 \pm 6.3$ & 0.020 & $18.6 \pm 25.7$ & $-1.2 \pm 6.5$ & 0.001 \\
\hline Treatment & $15.6 \pm 26.3$ & $4.8 \pm 10.7$ & 0.331 & $11.7 \pm 18.1$ & $2.1 \pm 7.2$ & 0.110 \\
\hline Medication & $5.1 \pm 16.2$ & $0.0 \pm 15.0$ & 0.458 & $3.6 \pm 17.2$ & $2.1 \pm 7.2$ & 0.873 \\
\hline Total score & $15.0 \pm 17.1$ & $1.5 \pm 14.5$ & 0.057 & $14.2 \pm 15.4$ & $2.1 \pm 15.2$ & 0.002 \\
\hline
\end{tabular}

Data are change in quality of life, presented as mean $\pm \mathrm{SD}$, unless otherwise stated. DUX-25: the Dutch Children Academisch Ziekenhuis Leiden (AZL)-ToegepastNatuurwetenschappelijk Onderzoek (TNO) Quality of Life questionnaire; TACQOL: the TNO-AZL Children Quality of Life questionnaire. p-values were calculated using the Mann-Whitney test between groups. $\mathrm{p}<0.05$ was regarded as significant.

Two studies on disease-specific-HRQoL after the start of asthma medication in medication-naive children were found $[7,23]$. The changes (effect size) in TACQOL-asthma scores in the current education-exercise group were similar to the changes in the one study [7], but were slightly smaller than changes in the other [23]. Changes in these studies were greater than the minimal important change for the Paediatric Asthma Quality-of-Life Questionnaire [24].

The HRQoL changes seen in the present study also reach the level of clinical importance (effect sizes $>0.50$ ). What is new is the finding that clinical important changes can be found after education-exercise in children taking asthma medication. It is also new that effects were shown in the self and proxy reports of generic and asthma-specific measures.

It remains uncertain which component of the present training programme may have contributed to the positive effects on quality-of-life, as differential effects were not studied [25]. However, the educational programme used [8] has proven effects on anxiety and coping, due to better self-management [8]. As the current authors were trained in this educational programme [8], it was hypothesised that improved coping and anxiety, though not measured, may have been a component that contributed to improved HRQoL.

Improved subjective feelings may have been another component contributing to the observed HRQoL improvements.
The TACQOL(-asthma) measures used incorporate both the number and perception of health problems in the scoring (fig. 2). This makes the TACQOL sensitive to changes that are consistent with improved perceptions and qualities of health problems, even in the face of unchanged quantities.

It is unlikely that medication change or better inhalation technique had sufficient effect on HRQoL changes. The comparison between children with and without alteration of medication showed similar HRQoL improvements in both groups.

\section{Other methodological considerations}

The present findings are applicable only in children aged 712 yrs who suffer a substantial loss of well-being from persistent asthma symptoms, despite paediatric care.

Although the current study included a small number of children, this was sufficient according to the power analysis carried out in advance. The population was selected, as children with low HRQoL scores (pre-defined self-reported DUX-25 total score $<$ P10) were eligible to enrol, and they represented a quarter of children with asthma. Willingness to participate was greater $(75 \%)$ than the one-third expected from other studies $[26,27]$, and attendance by children and parents was high. The minimisation procedure was used to reduce the effects of selection on the findings. It was assumed that the low drop-out percentage prevented further selection bias. 


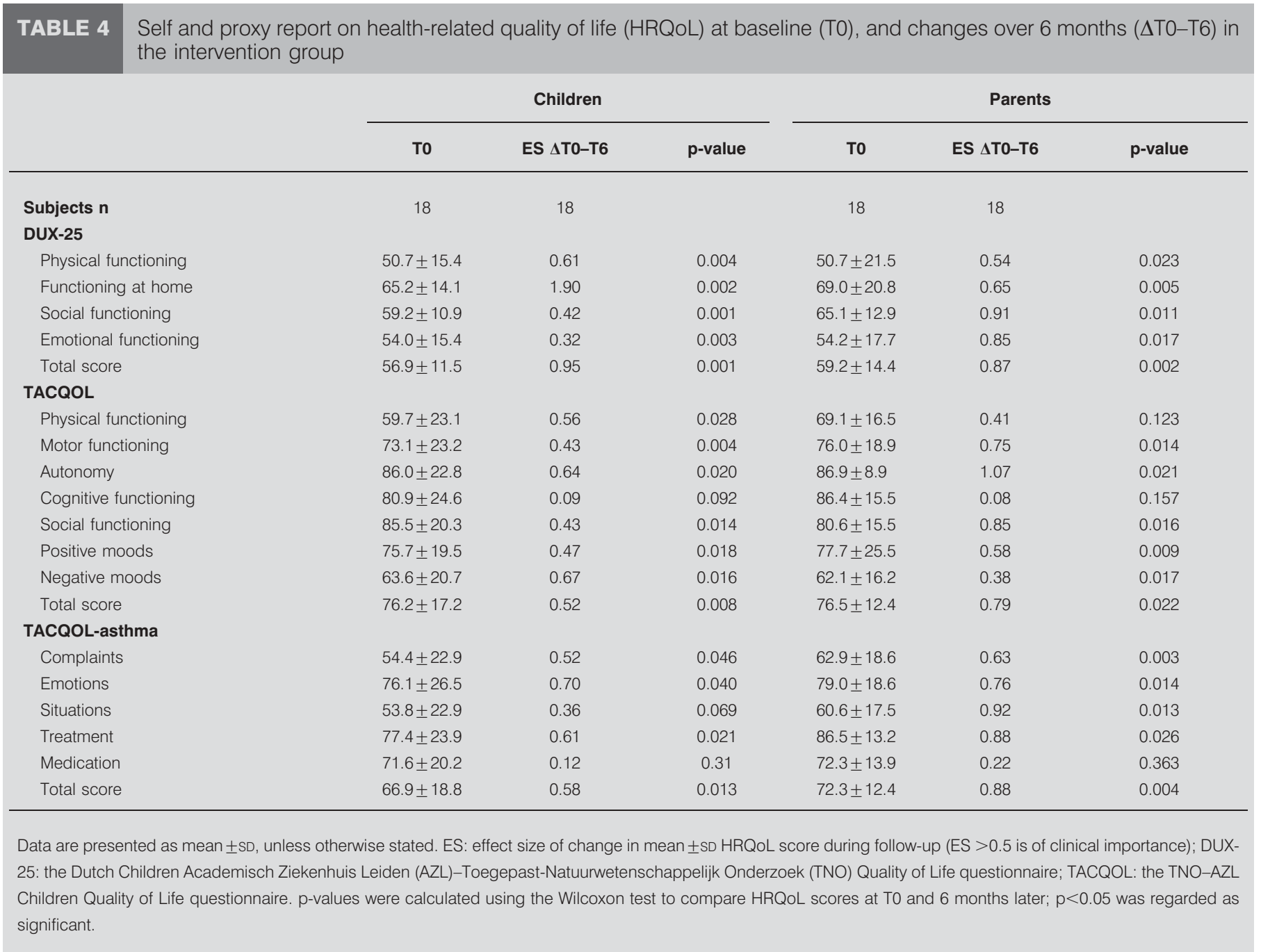

The present findings need to be reproduced in children with asthma and a normal HRQoL. Further study is needed to draw conclusions about long-term effects [26].

The message of the present study would be that, in addition to monitoring pulmonary function and disease-specific status in childhood asthma, paediatricians must monitor generic wellbeing, as a screening measure to recognise "unhappy" children. Happiness can be gained from an education-exercise programme that may enable these children to achieve better self-management of asthma, leading to less morbidity and greater well-being.

\section{ACKNOWLEDGEMENTS}

The current authors would like to thank the team of the Dept of Child Rehabilitation (Centre for Rehabilitation, University Medical Centre Groningen, Groningen, The Netherlands). C. van Baak, E. Beens, A. Swart, M. Eskes and S. Pariger, for the development and teaching of the training programme, and $\mathrm{H}$. Eeftingh for the distribution and collection of questionnaires, as well as the parents and children for their participation in the programme and in the measurements.

\section{REFERENCES}

1 Newacheck PW, Taylor WR. Childhood chronic illness: Prevalence, severity and impact. Am J Public Health 1992; 82: 364-371.

2 van der Wal MF, Uitenbroek DG, Verhoeff AP. Toegenomen percentage basisschoolkinderen met astmatische klachten in Nederland 1984/'85-1994/'95; een literatuuronderzoek. [Increased percentage of primary school children with asthmatic symptoms in the Netherlands 1984/85-1994/95: a literature review.] Nederlands Tijdschrift Geneeskunde 2000; 144: 1780-1785.

3 Korppi M, Remes K. Asthma treatment in schoolchildren: lung function in different therapeutic groups. Acta Paediatr 1996; 85: 190-194.

4 Rabe KF, Vermeire PA, Soriano JB, Maier WC. Clinical management of asthma in 1999: the Asthma Insights and Reality in Europe (AIRE) study. Eur Respir J 2000; 16: 802-807.

5 Guevara JP, Wolf FM. Effects of educational interventions for self management of asthma in children and adolescents. Systematic review and meta-analysis. BMJ 2003; 326: 1308-1317. 
6 Garrod R, Bestall J. Pulmonary rehabilitation: a physiological and psychological perspective. Crit Rev Phys Rehab Med 2001; 13: 265-281.

7 Kelly CS, Morrow AL, Shults J, Nakas N, Strope GL, Adelman RD. Outcomes evaluation of a comprehensive intervention program for asthmatic children enrolled in Medicaid. Pediatrics 2000; 105: 1029-1035.

8 Colland VT. Learning to cope with asthma: a behavioral self-management program for children. Patient Educ Couns 1993; 22: 141-152.

9 Hart C, Chesson R. Children as consumers. BMJ 1998; 316: 1600-1603.

10 van Veldhoven NHMJ, Vermeer A. Children with asthma and physical exercise: effects of an exercise program. Clin Rehab 2001; 15: 360-370.

11 Kolsteren MM, Koopman HM, Schalekamp G, Mearin ML. Health-related quality-of-life in children with celiac disease. J Pediatr 2001; 138: 593-595.

12 Verrips GH, Vogels T, Verloove-Vanhorick SP, et al. Health-related-quality-of-life measure for children: the TACQOL. J Appl Therapeut 1997; 4: 357-360.

13 Theunissen NCM, Vogels AGC, Koopman HM, et al. The proxy problem: child report versus parent report in healthrelated-quality-of-life research. Qual Life Res 1998; 7: 387-397.

14 Vogels T, Verrips GH, Verloove-Vanhorick SP, et al. Measuring health-related quality-of-life in children: the development of the TACQOL parent form. Qual Life Res 1998; 7: 457-465.

15 Flapper BCT, Koopman HM, Ten Napel C, van der Schans CP. Validation of the TACQOL-asthma, a disease specific measure of health related quality-of-life for children with asthma and their parents. Chronic Respir Dis 2006; 3: 65-72.

16 American Thoracic Society. Standards for the diagnosis and care of patients with chronic obstructive pulmonary disease (COPD) and asthma. Am Rev Respir Dis 1987; 136: 225-244.

17 Hofstra WB, Sterk PJ, Neijens HJ, Kouwenberg JM, Mulder PG, Duiverman EJ. Occurrence of a late response to exercise in asthmatic children: multiple regression approach using time-matched baseline and histamine control days. Eur Respir J 1996; 9: 1348-1355.

18 Hoekstra MO. Treatment of asthma in children; revised guidelines by pediatric pneumologists. Dutch Pediatric Respiratory Society. Ned Tijdschr Geneeskd 1997; 141: 2223-2229.

19 Clark NM, Partridge MR. Strengthening asthma education to enhance disease control. Chest 2002; 121: 1661-1669.

20 Altman DG, Bland JM. Treatment allocation by minimisation. BMJ 2005; 330: 843.

21 Middel B, Stewart R, Bouma J, van Sonderen E, van den Heuvel WJ. How to validate clinically important change in health-related functional status. Is the magnitude of the effect size consistently related to magnitude of change as indicated by a global question rating? J Eval Clin Pract 2001; 7: 399-410.

22 Cano-Garcinuño A, Diaz-Vázquez C, Carvajal-Urueña I, Praena-Crespo M, Gatti-Viñoly A, Garcia-Guerra I. Group education on asthma for children and caregivers: a randomized, controlled trial addressing effects on morbidity and quality of life. J Investig Allergol Clin Immunol 2007; 17: 216-226.

23 Lemanske RF, Nayak A, McAlary M, Everhard F, FowlerTaylor A, Gupta N. Omalizumab improves asthma-related quality of life in children with allergic asthma. Pediatrics 2002; 110; e55.

24 Juniper EF, Guyatt GH, Willan A, Griffiths LE. Determining a minimal important change in a diseasespecific quality of life instrument. J Clin Epidemiol 1994; 47: 81-87.

25 Osman LM, Calder C. Implementing asthma education programs in paediatric respiratory care: setting, timing, people and evaluation. Paed Respir Rev 2004; 5: 140-146.

26 Moher D, Schulz KF, Altman DG. The CONSORT statement: revised recommendations for improving the quality of reports of parallel-group randomised trials. Lancet 2001; 357: 1191-1194. 